\title{
Inmunología de la mucosa oral: Revisión
}

\section{Immunology of oral mucosa: A review}

\author{
Casariego Zulema J*
}

\section{RESUMEN}

Durante los últimos 50 años numerosas publicaciones han tratado de explicar los cambios inmunológicos en relación con exclusivas o determinadas enfermedades.

El objetivo de esta presentación es realizar una revisión sobre lo publicado hasta el momento sobre la respuesta del sistema inmune innato y adaptativo en relación con la mucosa oral, un panorama sobre el rol o roles de las células inmunes, citoquinas, receptores, factores de crecimiento y otros productos secretorios y el los distintos elementos inmunológicos que actúan sobre la mucosa oral asociados con los estados de salud, inflamación, stress crónico, desregulación inmune, longevidad tolerancia inmune e inmunosenescencia.

Palabras clave: cambios inmunológicos, desregulación inmune-tolerancia-inmunosenescencia.

\section{SUMMARY}

During the last 50 years several papers have been put forward to explain induce immunological changes in relationship with exclusive or determinated oral diseases.

The objective of this presentation is to make a rewie about what is published at the moment about of innated and adaptative immune response, in relationship with oral mucosa, and an overwie of the role (s) of immune cells, cytoquines, receptors, grow factors, and other secretory products associated with health, inflammation, chronic stress, Immune dysregulation aging, inmuno tolerance and inmunosenescence.

Key words: Chronic stress-dysregulation-aging-immunosenescence.

Fecha de recepción: 15 de enero de 2012.

Aceptado para publicación: 15 de abril de 2012.

* Ex Profesora Académica de Patología y Clínica Estomatológica de la Facultad de Odontología de la Universidad de La Plata.

Profesora Académica de Farmacología y Terapéutica de la Facultad de Odontología de la Universidad de La Plata.

Directora de la Carrera de especialización de Clínica Estomatológica de la Pontificia Universidad Católica Argentina. Buenos Aires.

Docente invitada de Infectología, de la Facultad de Medicina de Buenos Aires, Unidad en el Hospital de Agudos Juan A. Fernández Buenos Aires.

Casariego Zulema J. Inmunología de la mucosa oral: Revisión Av. Odontoestomatol 2012; 28 (5): 239-248.

Esta presentación tiene como objetivo revisar el comportamiento de sus estructuras, especialmente de la mucosa bucal, relacionándolas con los diferentes elementos del sistema inmune, en diferentes estados fisiológicos.
Es digno de destacar tres características fundamentales de la mucosa bucal y demás estructuras vecinas que por su complejidad explican la pluralidad del sistema inmune a este nivel. Primero: todas ellas se encuentra lubricadas por un fluído único, la sali- 
va, la cual posee elementos inmunológicos propios. Segundo: la mucosa bucal recubre en gran parte a los huesos maxilares, únicos huesos en los mamíferos que poseen piezas dentarias y que conforman otro órgano, el periodontal. Tercero: desde la sexta semana de vida intrauterina comienzan a formarse los folículos dentarios, que bajo ciertas circunstancias pueden originar los tumores odontogénicos, también únicos en el tejido óseo general.

De tal modo que se ve la necesidad de repasar someramente las diferentes estructuras de la mucosa oral con:

1. Sus células epiteliales, los queratinocitos., la membrana basal (MB) y sus proteínas, el tejido conectivo y matriz extracelular (MED) en su relación con el sistema inmunológico innato en una primera visión.

2. La relación de los elementos mencionados anteriormente con los diferentes representantes del Sistema Inmune adaptativo, linfocitos T y B, células mastoides, anticuerpos, citoquinas, interleuquinas, factores de crecimiento y transmisión, etc.

3. Interrelación con la microflora saprófita y patógena, receptores Toll, moléculas de adhesión, saliva, sistema de mieloperoxidasa.

4. Mecanismos de tolerancia oral.

5. Referencias a algunas enfermedades bucales de base inmunológica

6. Aging e Inmunosenescencia de los tejidos bucales.

\section{LA SUPERFICIES MUCOSAS EN LOS MAMÍFEROS, EN GENERAL, ESTÁN PROTEGIDAS POR EL SISTEMA INMUNE}

La mucosa bucal se presenta constituida por el epitelio y el tejido conectivo, separados por la membrana basal (MB). Funciona como una barrera protectora a través de su estrato córneo. En las zonas más delgadas posee interesantes propiedades absorventes. El estrato granuloso ayuda a frenar la colonización extra oral y el estrato espinoso, con la incorporación del complejo plasma-membrana-desmosomas, representa un mecanismo de conservación de la estructura. Si alguno de estos elementos se alteran, pueden aparecer enfermedades inflamatorias, autoinmunes y/o neoplásicas benignas o malignas.
Las características de la inmunidad en la mucosa oral conforman un panorama especial (1).

Si comenzamos por considerar a los queratinocitos, ante una injuria reaccionan expresando citoquinas: la Interleuquina 18 (IL-18), la cual es una mediadora de inflamación en la inmunidad innata, la IL-37 y las Beta defensinas, en respuesta a estímulos inflamatorios provenientes de lipopolisacáridos (LPS), de ácido lipoteitoico o de interferón (IFN). Se adjudica también a los queratinocitos la secreción de la interleukina beta 1 (IL-1B) y la IL-6, el factor de Necrosis Tumoral (TNF alfa) y el factor estimulante de colonias de granulocitos y macrófagos (TGM-CSF), elementos inmunológicos presentes del sistema adaptativo (2).

Una de las actividades biológicas más importantes de la IL-1 es la capacidad de activar los linfocitos T mediante el aumento de la producción de IL-2 y sus receptores. Recordamos que la IL-1 estimula además la adherencia celular endotelial de los leucocitos mediante el estímulo de las moléculas de adhesión I-CAM, V-CAM y Selectina I, importantes en el mantenimiento y la intercomunicación de las células epiteliales (32).

La interleukina 6 (IL-6). media a la vez la activación, el crecimiento y diferenciación de las células $T$.

El factor de necrosis tumoral, es una citoquina, procesada por los neutrófilos, mastocitos, linfocitos, NK, células endoteliales y por los queratinocitos. Constituido por dos proteínas homólogas, alfa y beta, el Factor de Necrosis Tumoral alfa (TNF-alfa) es el factor estimulante de colonias de granulocitos y macrófagos (TGM-CSF) (1), potentes activadores de neutrófilos para la adherencia, quimiotaxis, degranulación y estallido respiratorio, factores decisivos en la inflamación.

Se ha adjudicado a los queratinocitos además, la producción del factor transformante de crecimiento beta (TGF-beta) con sus receptores. Este péptido, desempeña efectos estimuladores e inhibidores en numerosos tipos de células. Es un estimulante importante de fibrosis y promueve la cicatrización de las heridas, por lo cual, su presencia es relevante para la mucosa bucal. Por último, la interleukina 8 (IL-8) y la IL-33, ésta última expresada en células 
epiteliales bronquiales, fibroblastos células del músculo liso, macrófagos, y CDs, también se expresan en los queratinocitos.

Los epitelios, por medio de su membrana basal, se relacionan con la matriz extracelular (MEC) a la cual actualmente se le reserva un papel inmunológico relevante por su relación con la inflamación, la reparación de los tejidos, la alergia, la autoinmunidad, las infecciones, la necrosis, la lisis y la apoptosis.

Las membranas citoplasmáticas y los citoesqueletos con sus proteínas desmoglobina y dermocolina, se asocian a los filamentos intermedios y mantienen la integridad estructural de las células. En el tejido conectivo de la mucosa oral, los colágenos y las proteínas como las fibronectinas, los proetínglicanos, la laminina, la tenascina, la vitronectina y, en especial la elastina, inducen la migración quimiotáctica de los péptidos y segregan enzimas líticas y radicales libres, ante una agresión (4).

El heparán sulfato, también presente en el conectivo subepitelial de la mucosa bucal y asociado al colágeno y demás proteínas de la matriz extracelular (MEC), modifica las propiedades de las membranas extracelulares, de sus propias células y de la membrana basal (MB), llevando a la creación de un nuevo orden en sus células basales. La proliferación del heparán-sulfato puede activar la función de las células presentadoras de antígenos, pegar o unirse a factores de crecimiento, a quemoquinas y citoquinas, presentar mediadores de inflamación en su forma activa a los fibroblastos y, facilitar la asociación con linfocitos $\mathrm{T}$ y los leucocitos (la incorporación intra citoplasmática de los desmosomas y su defecto en la adhesión intercelular es un fenómeno ubíquitos exhibido por los queratinocitos epiteliales bajo condiciones patológicas) (5).

Hoy en día se interpreta el sistema inmunológico compuesto por elementos que están viviendo y actuando contínuamente en los estados de normalidad y salud, de enfermedad o "inflamando" ("inflamaging") (6), defendiendo, agrediendo, tolerando y envejeciendo ("aging") (7). Por lo cual, para mantener el equilibrio biológico de las estructuras de la mucosa bucal se necesita que este sistema funcione a escala molecular, discriminando entre lo propio y lo ajeno, entre lo agresivo y lo aceptable, entre el todo y la molécula, respondiendo en forma evolutiva ante un medio interno y externo complicado.

La superficie mucosa oral está integrada por un sistema inmune altamente desarrollado y especializado, llamado tejido linfoide asociado a las mucosas (MALT) (8). Recordar la localización de centro linfoideos no solo en el orofarins (amígdalas) si no también en el paladar (límite entre el duro y blando) y gíngiva adherente vestibular, palatinal y lingual y glándula parótida principalmente) (9).

La mayoría de los linfocitos intraepiteliales de las mucosas en los seres humanos son los $T$ y la mayoría CD8+. Estos muestran una diversidad limitada de receptores para antígenos, por lo cual son de una especificidad limitada, diferente a la mayoría de los linfocitos. Además de linfocitos dispersos, el sistema inmunitario de las mucosas contiene tejidos linfáticos organizados a imagen de las placas de Peyer del intestino delgado y de los folículos linfáticos del bazo (10).

La respuesta inmunitaria a los antígenos orales es diferente de las respuestas en otras localizaciones. Así, las altas concentraciones de anticuerpos de $\operatorname{IgA}$ asociados a los tejidos mucosos y, la tendencia a través de antígenos proteicos a inducir tolerancia en vez de activación de los linfocitos $\mathrm{T}$, distingue a la mucosa bucal (11).

Considerando que en el medio bucal intra y extracelular existe un campo afectado por una invasión microbiana saprófita constante, a la cual se agregan ocasionalmente distintos gérmenes patógenos, el contínuo tráfico de neutrófilos provenientes de los capilares gingivales en el surco gingival son atraídos por los péptidos del biofilm de la placa dental y por la IL- 8 del epitelio gingival, estables en la mayoría de los individuos, que mantienen la homeostasis del entorno. En un organismo inmunológicamente predispuesto se producen infecciones.

Está comprobado que existen competencia genética, mutaciones y síntesis de los péptido glicanos a través de los receptores de las bacterias. Éstos se ligan por un lado a las pieza dentarias y a la mucosa periférica y adherente o sea la gíngiva, y por el otro 
a las moléculas de la saliva. Los microorganismos estimulan las reacciones inmunitarias innatas en los cuellos gingivales de las piezas dentarias y sintetizan las citoquinas inflamatorias. La combinación de microbios y citoquinas, activan a las células dendríticas $C D$ las cuales pierden su adhesión a los epitelios y comienzan a expresar un receptor de quimocinas denominado CCR7, específico para las citoquinas que son producidos en las zonas $\mathrm{T}$ de los ganglios linfáticos (12). Estas células fragmentan a los antígenos en péptidos y los presentan asociados con las moléculas de superficie del CHM II, como ya se conoce, a los linfocitos $\mathrm{T}$.

Las células dendríticas, localizadas en el área de las células T de los órganos linfoides secundarios, incluyen una expresión de alta densidad en la superficie de CD40, CD83, moléculas coestimuladoras (CD80 y CD86) y el receptor de quemoquinas CCR7. Estas células presentadoras de antígenos CPA contribuyen en esta fase a la señalización de citoquinas produciendo IL-1, IL-5, TNF alfa, IL-12 e IL-15 (28).

Al producir luego IL-12, resultan ser los mediadores más eficaces para la diferenciación de TH2 (importante para que los antígenos puedan ser procesados por los macrófagos produciendo una respuesta Th1.

En la sangre periférica, las $C D$ son heterogéneas y comprenden, por lo menos, dos subpoblaciones de células inmaduras, células dendríticas mieloides (CDM) (DCM, CD11c+) y células dendríticas plasmacitoides (CDP) (DCP, CD123+). Difieren en muchos aspectos fenotípicos y funcionales porque provienen de un linaje distinto y expresan diferentes patrones de receptores tipo Toll (TLR) y de receptores de citocinas. Secretan diferentes citocinas, se ubican en órganos linfoides y no linfoides, y circulan en la linfa aferente. Por sangre periférica llevan diferentes nombres según su ubicación:

a) En regiones $T$ dependientes de órganos linfoides: Células interdigitantes.

b) En centros germinales de los folículos secundarios en áreas de linfocitos B: CD foliculares.

c) En órganos no linfoides: células de Langerhans situadas en epitelios planos estratificados de piel y mucosas.

d) En linfa aferente, se las conoce como células veladas. e) En sangre periférica: las CD son escasas.

f) En otros órganos (corazón, hígado, parénquima pulmonar, lámina propia del intestino): se denominan células intersticiales.

g) En cerebro, son células de la microglia que se asemejan a células dendríticas por su forma y por sus marcadores de membrana) (13).

Tanto las células dendríticas plasmacitoides (CDP) como las de Langherans (CL), se encuentran en la cavidad bucal. Las CDP se encuentran de preferencia en la circulación, desde donde migran directamente a los órganos linfoides secundarios. También se ubican en el orofarins. Activadas, producen grandes cantidades de IFN- $\alpha$. Cada CDP produce hasta 1.000 veces más IFN- $\alpha$ que cualquier otra célula en el organismo. Las CDP tienen menor potencial como presentadoras de antígenos, pero, tienen un compromiso mayor en la inducción de las respuestas tipo Th2. Juegan un papel importante en la protección contra las infecciones producidas por virus y gérmenes oportunistas. Desde el punto de vista de los marcadores fenotípicos de las CD son muy heterogéneas, pero todas son CD 205. CD 1 a y CD 1 b. Son típicos de células de Langherans el CD207 y CD 1c, y el CD 83 (14).

Coexistiendo con los elementos anteriormente mencionados, es interesante reconocer especialmente en la mucosa oral, en el orofarins y en el órgano lingual, la presencia de receptores del sistema nervioso periférico, del tipo alfa y beta, especialmente los receptores Beta adrenérgicos cuya estimulación y selectividad son de importante consideración y relación con este tema.

Los linfocitos $B$ de las tonsilas contienen alrededor de 600 receptores Beta 2 por célula, y los linfocitos T, 200. Si se recuerda al receptor Beta 2 por su influencia en la vasodilatación muscular, en la estimulación de la adenilciclasa para formar AMPc y como dilatador, a partir de la molécula intermediaria guanín nucleótido sensitiva para el influjo del $\mathrm{Ca}++$ ), se entiende, debido a su estimulación, que las mucosas sean más fluidas y sensibles, favoreciendo la aparición de más receptores Beta, que permanecen generalmente escondidos o crípticos y que están distribuidos en todo el tejido conjuntivo cerca de los capilares mucosos orales. 
Por lo cual, el aumento de receptores beta totales de membrana produce aumento del estado de hipersensibilidad (15).

Considerando a los mastocitos (16) existentes en el tejido subepitelial lingual, en las criptas amigdalinas, en las tonsilas y en la mucosa de las fauces, como ricos depósitos de receptores Beta 2, estimuladores de los receptores Beta adrenérgicos y al 3'5’AMPc, pueden inhibir el mucus, en caso de inflamación e injuria a través del hipofuncionamiento de las glándulas submucosas provocando xerostomía. Están presentes en el tejido conectivo, debajo de la MB en la mucosa oral y cercanos siempre a un capilar sanguíneo. Si son estimulados, degranulan sus contenidos a través de sus receptores. Responden, desde el punto de vista inmunológico al alergeno IgE (FceR1 cross linking), al Antígeno IgG2a //IgG ${ }^{4}$ (Fc gamma $\mathrm{R}$ cross linking), a las anafilotoxinas $\mathrm{C} 3^{\mathrm{a}} \mathrm{C} 5 \mathrm{a}$ y a la proteína básica mayor del eosinófilo. La reacción del mastocito a la sustancia $\mathrm{P}$, a la Polimixina-B, a los venenos, a la irradiación y el calor y a las citoquinas IL-3 e IL-4 no es inmunológica. La reacción frente a los productos bacterianos, y virus lo realiza a través de su receptor Toll-like). Recordemos que los gránulos del mastocito contienen histamina, tryptasa, carbopéptidos, quinasa, heparina y condroitín-sulfato-E. En su núcleo, la expresión de genes producen varias interleuquina, como la IL-3, 4, 5, 6, 7, 8, 10 y 13 , el factor de crecimiento de los macrófagos GMCSF y el factor de necrosis tumoral TNF como los más reconocidos (17).

Los eosinófilos, si bien no pertenecen a la MEC, son células circulantes que responden a la eotaxina mediante sus receptores CCR-3, y participan en reacciones inmunológicas de la mucosa bucal. La IL-5 es la mayor proteína eosinófila. Además de estimular la producción de estas células y su liberación en la médula ósea, incrementa su número y su secreción. Si bien estas características son de crucial importancia en los temas de alergia y anafilaxia, no se puede obviar el hecho de las reacciones de sensibilidad de la mucosa bucal, juntamente con la proliferación de las células cebadas y el crecimiento de los mastocitos.

La integridad de la estructura mucosa, se logra mediante la adhesión a nivel molecular llevada cabo por las proteínas de adhesión. Han sido identificadas ultraestructuralmente en el espesor de la membrana celular y adyacentes a los componentes de la MEC. Interactúan con los filamentos de actina, fibronectina, talina, vinculina y otras proteínas del citoesqueleto manteniendo la estructura de los tejidos. Las integrinas situadas en las paredes de los vasos grandes, expresan los marcadores alfa 5 beta 1 y alfa 5 beta 3. mientras que las encontradas en los capilares de las mucosa y submucosas. expresan alfa 1 beta 1 y alfa 2 beta 1 . Requieren para la adhesión la presencia de colágeno y laminina (presentes en la MB de los epitelios de las mucosas) $(18,19)$.

Los receptores de las celulares de la mucosa oral actúan también como moléculas de adhesión y de señalización (20) y participan en la embriogénesis, crecimiento y diferenciación celular, en la reparación de heridas, inflamación y diseminación metastásica en caso de cáncer de mucosa bucal. Durante la presentación antigénica de las CPA, las integrinas se identifican también como moléculas accesorias, facilitadoras del reconocimiento antigénico.

Integrando el compartimento intracelular y extracelular, por medio de sus dominios intracitoplasmáticos, el transmembranoso y el dominio extracelular, estas moléculas se expresan en distinta proporción en las células epiteliales y endoteliales, y para leucocitos, fibroblastos y plaquetas sanguíneas. Ellas son las Beta 1 (CD29), Beta 2 (CD18), y Beta 3 (CD61) (21).

En la mucosa oral, las Selectinas (lectinas $\mathrm{Ca}++$ ) se ligan con oligosacáridos o mucinas. En esta localización, se distinguen la L-selectina, que posee tres ligandos: el CD34 o sialomucina endotelial, el MadCAM-1 endotelial de las placas de Peyer y anillo de Waldeyer, y el GlyCAM-1 de los ganglios linfáticos. El complejo cadherina E/catenina es el principal sistema de conexión entre las células epiteliales La presencia de la saliva, proveniente de las glándulas salivales que desembocan en la cavidad bucal juega un rol preponderante en la salud de la mucosa bucal. En un ambiente heterogéneo, con una población mixta de microorganismos, la saliva mediante sus enzimas, la lisozima y la lactoperoxidasa interrumpe la integridad de las paredes microbianas. Por otro lado, El mayor anticuerpo que se encuentra en el fluido salival es el sistema secretor de la inmunoglobulina A 
secretoria (IgA-s). Dos moléculas de IgA son sintetizadas por las células plasmáticas asociadas a las glándulas salivales. Esta inmunoglobulina A dimérica, se une por medio de su cadena $\mathrm{J}$ a un receptor, para originar una forma polimérica que se une a las células del epitelio de la membrana glandular. Este complejo es transportado a través de las células epiteliales en una vacuola endocítica y entra en el ducto de la glándula salival por su superficie luminar.

Ya enclavada en el receptor, segrega la IgA en la saliva con una porción de la proteína receptora. De las dos subclases de IgA, IgA1 y IgA2, la segunda es la que predomina en la saliva (23).

Acompañando a la IgA-s se presentan también la IgG-s y la IGM-s las cuales inhiben la adherencia de los microorganismos a la mucosa, y neutralizan a los virus. En la saliva, el sistema de las metaloproteinasas es bactericida en presencia de $\mathrm{H}_{2} \mathrm{O}_{2}$ igualmente que el sistema peroxidasa de las aglutininas. El 98\% de los neutrófilos permanecen no reactivos, incapaces de fagocitar y alertas, durante el período de quietud inmunológica (24).

Sintetizando, si consideramos una mucosa oral inflamada, podemos adoptar y adaptar el concepto que se produce un reclutamiento de todos los elementos del sistema inmunológico en la zona donde hubo una injuria, con el fin de eliminar aquello que lo provoca, involucrando una reacción compleja del tejido conjuntivo vascularizado.

Si existe presencia microbiana, el reconocimiento de los microorganismos patógenos, portadores de sus receptores PAM, es llevado cabo por los receptores Toll, ubicados en las membranas de los neutrófilos, de los macrófagos y de las Células de Langerhans, diferenciando a los patógenos de los saprófitos $(25,26)$.

La reacción inmunológica que comienza con la endocitosis y fagocitosis de los antígenos por los neutrófilos, los macrófagos y las células dendríticas en los órganos linfoides o por las células de Langherans (27), sigue con su activación y la expresión de $T N F$ alfa, IFN gamma, e IL-2, estimulándose a la vez a los macrófagos y a los linfocitos citotóxicos. La respuesta humoral se presenta con secreción de IgG, IgE, IgA y producción de mastocitos y eosinófilos.
Usando el Interferón gamma, las células TH1 pueden inhibir la función de las TH2. Si bien la inflamación aguda se caracteriza por alteraciones vasculares, edema, e infiltración neutrofílica, la fagocitosis de los macrófagos promueve el estallido respiratorio y la activación de la ciclooxigenasa e induce la degranulación de las células cebadas y la liberación de Histamina. Al mismo tiempo se induce la síntesis de citoquinas pro inflamatorias como la IL- 1 y la IL-6 y el TNF alfa por los monocitos (28) y, aumento y estimulación de los fibroblastos y de secreción de las Integrinas Beta 2. Éstas, provocan la producción de leucotrienes B4 y del ácido 5 HETE.

En la cavidad bucal, las infecciones son en general persistentes y reflejan infecciones sistémicas como la de Tuberculosis, Sífilis, Lepra y micosis. Estos microorganismos son de baja patogenicidad e inducen una respuesta inmunitaria de hipersensibilidad. En ocasiones la respuesta inflamatoria en los tejidos bucales adopta la forma de un patrón morfológico tipo úlceras y pápulas formando placas, erosiones, úlceras o granulomas como en el caso de la sífilis, o tuberculomas, lepromas y en histoplasmosis y blastomicosis entre otras. Estos granulomas, verdaderos laboratorios inmunológicos, consisten en una acumulación microscópica de macrófagos transformados en células epiteloides, rodeada por un collar de leucocitos mononucleares, principalmente linfocitos y en ocasiones, células plamáticas. Lasa lesiones en la mucosa bucal acompañan al resto del organismo. Cada una de estas infecciones sistémicas tienen un comportamiento inmunológico diferente, desde la infección por Mycobacterium tuberculoso, con reacción celular Th1 y abundante producción de IFN gamma, a la lepra border line lepromatoide, con ausencia de éste y la lepra lepromatosa con estado de anergia (26).

\section{TOLERANCIA INMUNOLÓGICA EN LA MUCOSA BUCAL}

Conociéndose a la tolerancia inmunológica como la capacidad de bloquear la respuesta frente a un antígeno específico con el cual el sistema inmunológico ha interaccionado previamente en condiciones particulares, se reconoce este mecanismo en el ámbito de la mucosa oral. 
Entre todas las definiciones existentes de tolerancia, mencionamos aquí la que establece que, se conoce como tolerancia inmunológica la capacidad de bloquear la respuesta frente a un antígeno (Ag) específico o concreto, con el cual el sistema inmunológico ha interaccionado previamente en condiciones especiales.

El sistema inmune de las mucosas en general y de la mucosa oral en particular está delicadamente conformado para permitir ciertos antígenos, por ejemplo los de los alimentos y aceptarlos, o sea, no reaccionar contra ellos o "forma tolerogénica" y, en cambio, reaccionar desde el punto inmunológico frente a antígenos infecciosos.

Pareciera lógico que estos mecanismos de tolerancia se centren en los linfocitos $\mathrm{T}$ debido al papel clave que éstos tienen en la respuesta inmune.

Si consideramos los tres mecanismos de tolerancia que se adjudican a los linfocitos $\mathrm{T}$, central, periférica e inmunológica, se tendrá especial atención en las señales que en la lámina propia los linfocitos CD4+ TCR alfa beta, al interactuar con el Ag, producen una respuesta inmune o supresión. En el primer caso, la activación del factor NF-kB es fundamental para el desarrollo de la respuesta inflamatoria a nivel de las mucosas. La entrada de Ags alimentarios desencadenará el mecanismo de tolerancia oral con la inducción de anergia, eliminación clonal y/o generación de células supresoras que liberarán el factor central, protagónico de tolerancia en las mucosas: el TGF-beta.

Si este factor se expresa en forma contínua o sostenida, se producirá un estado de respuesta periférica Th1 y reacción inmune por IgA a nivel local.

Esto significa que ante la presencia e injuria de un factor infeccioso se producirá una lucha entre la aparición de las citoquinas proinflamatorias y las respuestas Th1 o Th2.

Ante la presencia de la flora microbiana oral mixta, el predominio de las bacterias gram positivas se presentan como inductoras de secreción de IL-12 (proinflamatoria) mientras que las gram negativas estimulan con preferencia a la IL-10. Esta interleuquina es inmunosupresora anti el desafío antigénico.
Puede ocurrir también el silenciamiento por medio de los linfocitos CD8+, TCR gamma delta.

Sintetizando, la inducción de tolerancia oral parece fundamentarse en la inducción de anergia de las células T. Este proceso es mucho más complejo y no está aún totalmente resuelto (27).

\section{¿SUIFREN LOS TEJIDOS DE LA CAVIDAD BUCAL EL DETERIORO DE LA EDAD Y LA SENESCENCIA?}

El envejecimiento ha sido estudiado desde hace años, habiéndose postulado varias teorías para explicarlo Recientemente, la acumulación de evidencias sugiere que, los cambios en la comunicación entre el sistema inmunológico y el sistema nervioso. combinaciones neuroendocrinas, el desgaste concomitante o pérdida de homeostasis y la resistencia al stress, podrían ser las causas fundamentales de la senescencia fisiológica, llamada hoy en día "Aging" (28).

En pacientes de edad avanzada observamos a diario un incremento de vulnerabilidad a las infecciones, al cáncer y a las enfermedades autoinmunes. Mucosas laxas, músculos sin tono, incontinencia salival o por el contrario sequedad de boca (xerostomía), pérdida del gusto y otras tantas falencias acompañan a este síndrome neuro-inmuno-endocrino de la senescencia también en los tejidos de la cavidad bucal y anexos.

"Aging es el resultado del daño acumulado por oxidación deletoria en las biomoléculas causadas por la alta reacción de los radicales libres y especies reactivas de oxígeno ROS producidos en nuestras células como resultado del uso de oxígeno" (29).

Su teoría se centra en el daño mitocondrial causado por los radicales libres que producen una pérdida de energía biológica que conduce a aging y a la muerte de las células del organismo. El aumento de compuestos oxidantes e inflamatorios y la disminución de las defensas antioxidantes, aumentadas en las células fagocíticas, produciría mecanismos intracelulares como la activación de NF-kB en los leucocitos, afectando a las células especialmente a aquellas del sistema regulador. 
Borkan and Norris realizaron un estudio longitudinal sobre 1.000 pacientes de edad avanzada, llegando a la conclusión que con la edad decrecen las funciones que son más beneficiosas, tales como la respuesta linfoproliferativa de la actividad de los NK que nos protege de células tumorales, una declinación de la IL-2 quien regula la quimiotaxis y la fagocitosis y el adecuado nivel de ROS en los fagosomas.19-24 (30).

En particular, la toxicidad de los NK está asociada con la edad y la longevidad. Mientras que baja NK, la citotoxicidad está asociada con aumento de morbilidad y mortalidad 82-85 (31).

Evidencias acumulativas soportan la existencia de cambios asociados con la edad en los componentes celulares del SI innato, incluyendo además de los NK, a las células dendríticas CD y los fagocitos. Un aspecto de la inmunosenescencia es la reducción del repertorio de las células CD8 debido a la acumulación de las células $T$ memoria y la reducción de las células T naive y la acumulación de los CD8- particularmente en el compartimento citotóxico (32).

El distress psicológico puede ser un importante factor de riesgo para la inmunosenescencia (32).

En particular se halló que los gerontes (estrictamente saludables) estaban más estresados ansiosos y depresivos que los jóvenes adultos. En paralelo con el stress psicológico se observó que los ancianos tienen un $45 \%$ más de producción de cortisol comparado con adultos jóvenes. Estos datos sugieren que gerentes sanos hay una activación significativa del eje hipotalámico-pituitaria-adrenal. Severas patologías asociadas con excesiva exposición a glucocorticoides (GC) incluyen atrofia de músculos, osteoporosis/hipercalcemia/hiperlipidemia, ateroesclerosis, diabetes tipo II y mayor depresión.

\section{CONCLUSIÓN}

La mucosa bucal merece sin duda un capítulo propio dentro de los estudios del sistema inmune.

Es de destacar que existen numerosos trabajos específicos sobre el comportamiento del sistema inmune en diversas enfermedades de la mucosa oral.
El mantenimiento de la homeostasis de la mucosa bucal es particularmente problemático ya que está en contacto permanente con un cantidad de microorganismos y antígenos heterólogos como los alimentos. Las células de Langerhans (CL) y la variedad de células dendríticas plamocitoides (CDP) son las principales células presentadoras de antígenos (CPA) de los epitelios planos estratificados y por ende, típicas de la mucosa oral. En ausencia de infección migran en un estado de latencia inmadura a los órganos linfoides donde inducen un estado de irresponsabilidad antigénica específica o tolerancia. Mediante varios mecanismos, inclusive la inducción de células $T$ reguladoras, desempeñan un rol de tolerancia oral tanto de Ags completos como de péptidos. En la actualidad, éste es el principal rol que la Inmunología le confiere a este tejido. La interrelación con otras ciencias nos permite arribar a un conocimiento más completo de los distintos elementos inmunes en el mantenimiento de salud y el manejo terapéutico de las distintas lesiones y enfermedades de la mucosa oral.

\section{BIBLIOGRAFÍA}

1. Walter DM. Oral mucosa Immunology. An overwiew. Ann Acd Med Singapore 2004;33 (Suppl):278-305.

2. Horiguchi Y, Firikawa F, Fujita M, Imamura S. Ultraestructural localisation of E-cadherin cell adhesión molecule on the cytoplasmastic membrana keratinocytes in vivo and in vitro. J Histochem Cytocehn 1994;42:1333-40.

3. Symington FW, Santos EB. Lysis of human keratinocytes by allogenic HLA-class specific cytotixic's cells keratinocytes ICAM-1 (CD54) and T cell LFA-1 (CD 1 $\left.{ }^{\mathrm{a}}-\mathrm{CD} 18\right)$ mediated enhanced lysis of IFN gamma treated keratinocutes. J Immunolol 1991;46:2169-75.

4. Casariego Z, Herrero T, Pombo T. Laminina 5, Vimentina y células mastoideas en el tejido perilesional de las úlceras aftosas recifivantes (RAU): estudio histológico e Inmunohistoquímico en pacientes $\mathrm{VIH}-1+$ reactivos y $\mathrm{VIH}$-1-negativos. Alergo Virtual set-dic-2000. 
5. lodish H, Berk A, Matsudaira P, Kaiser CA, Krieger MM, Scott MP, Zipursky SL, Darnell J. Integración de células en tejidos. 6.4. En: Lodish H, Berk A, Matsudaira P, Kaiser CA, Krieger MM, Scott MP, Zipursky SL, Darnell J. Biología Celular y Molecular. 5a ed. Panamericana, Buenos Aires, 2009. p. 973.

6. Cardinalli DP, Esquifito AL, Srinivasa NV, PandiPerumal SR: Melatonin and the Immune System in Aging, 2008;272-8.

7. Mónica de la Fuente. Role of neuroimmunomodulation in Aging. Neuroimmunomodutaltion 2008; 15:213-28.

8. Cawson RA, Beume WH, Barrett AW, Wreight JM. Pathology of Tumours of Head Tissues, 1998; Churchill Livingstone, Edinburg.

9. Waldron CA, Koh ML. Central mucoepidermoide cancer of jaws : report of the literature and discussion of the relationship to mucoepidermoide sialoodontogenic and glandular Odont-cyst. J Oral Maxillofac Surg, 1990;48:671-877.

10. Barnes L, Everson JW, Reichart. Papthology and genetic of head and neck tumours. WHO Classification of Tumours. 1995; Vol. 9 IARC. Press Lyon.

11. Sistig S, Spertini F. Secretory immunoglobulin A from mucosal protection to vacune development. Biol Chem 1999;380:1251-62.

12. Coronato S, Laguens GE, Spinelli OM, Salas MA, Di Girolano WD. Células dendríticas y su papel en patología. Medicina 1998; 58(2):209-18.

13. Culuyan HE, Jancic CC, Lutzky VP, Zittermann SI, Maffia P, Scimone ML, Burzyn D, Carnevale R. Células dendríticas: las células presentadoras de antígenos más eficientes. Implicancias en Inmunoterapia. En: Rabinovich Gabriel Adrián. Inmunopatología molecular: nuevas fronteras de la medicina. $1^{\text {a }}$ ed. Buenos Aires: Médica Panamericana, 2004;640.

14. Wright-Browne V, McClan KL, Ordóñez N. Physiology and pathophysiology of Dendritic cells. Human Pathology, may 1997; 26(5): $563-$ 79.

15. Page CP, Curtis NMJ, Sutter MC, Walker MJA, Hoffman BB. Farmacología integrada. Madrid: Harcourt España, 2008;555.

16. Walsh LS, Davis MF, Xu LS, Savage NW. Relationship between mast cell degranulation and inflammation in the oral cavity. J Oral Pathol Med 1995;24:266-72.

17. Stuart E Turvey et al. Inmunidad Innata JACI2010, 125:S24-32.

18. Makgoba MW, Sanders ME, Cinther Luce L, Gugel EA, Dustin ML, Springer TA, Shaw S. Functional evidence that intercellular adhesion molecules -1 (ICAM-1) is ligand for LFA-1 dependent adhesion in T cell mediated cytotocixity. Eur J Immunol 1998.

19. Scott P Commins et al. Moléculas mensajeras inmunológicas: citoquinas, Interferones y quimioquinas. JAQCI 2010;125:S53-72.

20. Verdickt GM, Savage NW, Dodd NM, Walsh LJ. Expresion of the CD54 (ICAM-1) and CD $11^{\mathrm{a}}$ (LFA-1) adhesión molecules in oral mucosal inflammation. J Oral Pathol Med1992;21:65-9.

21. Ye P, Simonian M, Chapple CC, Gibbins J, Kumar RK, Hunter N. Differential expresión of transforming grow factors-beta 1 , beta 2 , betra 3 and the type I,II,II, receptor in the epithelia of inflamed gíngiva. Pathology 2003;35:384-92.

22. Birkedal Hasen $H$. Roles of cytokines and inflammatory mediators in tissue destruction. $\mathrm{J}$ Periodont Res 1993;28:500.

23. Corthesy B, Spertini F. Secretory Immunoglobulin A: from mucosal protection to vacune development.Biol Chem 1999;380:125-62.

24. Lacraz S, Isler P, Vey E, Welgus HG, Dayer JM. Direct contact between $\mathrm{T}$ lymphocytes and monocytes is a major pathway for induction of metalloproteinase expresión. J. Bio. Chem. Sep 1994;269(35):22027-3. 
25. Setterfield J, Shirland PJ, Kerr-Muir M, et al. MMP a dual circulating antibody response with IgG and IgA signifies a more severe and persistent desease. Br J D 1998;138:602-10.

26. Botasso O, Bay ML, Besedovsky H, del Rey A. Immunoendocrine Alterations during Tuberculosis as an Integrated View of Disease Pathology. NeurolmmunoModulation 2009;16:68-77.

27. Hessle C, Anderson B, Wold AE. Gram positive bacteria are potent inducers of monocytic IL-12 while gram negative bacteria preferentially stimulate IL-10 production. Immunol Today 1999; 20-387.

28. Bauer, ME, De La Fuente M. An Introduction to Neuroimmunomodulation and Age. Neuroimmunomodulation 2008;15:211-2.

29. Merino Pérez J, López Hoyos M. De los mecanismos de tolerance a la autoinmunidad. Medicina 2000;8(26):1331-41.

30. Ogata K, Yokose N, Tamura H, An E, Nakamura K, Dan K, et al. Natural Killer cells in the later decades of human life. Clin Immunol immunopathol, 1997;84:269-75.

31. De la Fuente Mónica: Role of neuroimmunomodulation in Aging. Neuroimmunomodulation 2008; 15:213-23.

32. Collazol D, Luz C, Dornelles F, Cruz I, Bauer ME. Psychoneuroendocrine correlates of lymphocyte subsets during healthy aging. Mech Ageing Dev 2004;125:219-27.

33. Gouin JP, Hantsoo L, Kiecolt-Glaser JK. Immune Dysregulation and Chronic Stresss Among Older Adults: A Rewiew. Neuroimmunomodulation 2008; 15:251-9.

\section{CORRESPONDENCIA}

Casariego Zulema J

Bate. Mitre 1371-4M.

Buenos Aires.

Argentina

Correo electrónico: zulemacasariego@gmail.com 